\title{
Effect of Customer Citizenship Behavior on Elderly Customer Purchase Intention Based on Value Co-Creation Theory
}

\author{
Yan Huang, Feiyan Liu \\ School of Business, Nanjing Normal University, Nanjing, China \\ Email: hyanshe@qq.com
}

How to cite this paper: Huang, Y. and Liu, F.Y. (2019) Effect of Customer Citizenship Behavior on Elderly Customer Purchase Intention Based on Value Co-Creation Theory. Open Journal of Business and Management, 7, 650-665.

https://doi.org/10.4236/ojbm.2019.72044

Received: March 4, 2019

Accepted: April 1, 2019

Published: April 4, 2019

Copyright () 2019 by author(s) and Scientific Research Publishing Inc. This work is licensed under the Creative Commons Attribution International License (CC BY 4.0).

http://creativecommons.org/licenses/by/4.0/

\begin{abstract}
Under the value co-creation theory, the role behaviors in the interaction between customers and enterprises are constantly changing, from passive value recipients to common value creators. In the service situation, this paper takes the elderly customers as the investigation object, based on the value co-creation theory, and discusses the effect between customer citizenship behavior, aging attitude and elderly customers purchase intention. Through empirical analysis, it is found that the customer citizenship behavior has a positive impact on the purchasing intention of elderly customers. The aging attitude has a moderating effect between customer citizenship behavior and elderly customers purchase intention. On this basis, it provides relevant advice of customer relationship management and operation management for service enterprises from the perspective of promoting customer citizenship behavior and stimulating the purchase intention of elderly customer.
\end{abstract}

\section{Keywords}

Value Co-Creation Theory, Customer Citizenship Behavior, Elderly Customer, Aging Attitude, Purchase Intention

\section{Introduction}

Searching for information is one of the most critical stages in consumer purchasing decisions. Nowadays, in an era of information explosion, the sources of information are also various. Compared with the diversification of information obtained by young consumers, the source of information obtained by elderly consumers is mainly the recommendation of other consumers and the interaction with other consumers and service-oriented employees in the consumption 
process. Some consumer behaviors become the source of the latter's access to information, which in turn affects their purchasing decisions. Customer citizenship behavior is a concept that draws on the organizational citizenship behavior in the management field, and is a variety of behaviors that the customer voluntarily demonstrates beneficial to the enterprise [1]. Under the value co-creation theory system, customers participate in the value creation of enterprises as important asset resources. They use the products or services provided by enterprises and their own consumption capital to create value, from passive value recipients to common value creators. The enterprise transforms from a value creator to a value advocate, creating value through interaction with customers [2]. The interaction between members of the value network is the basic realization of value co-creation [3]. Consumers and enterprises, as equal value subjects, create value for themselves and each other through continuous interaction.

This study selects the elderly as the research object. On the one hand, it has certain practical significance and conforms to the national development policy. In the report of the 19th National Congress, General Secretary Xi Jinping stressed that it is necessary to actively respond to the aging of the population and accelerate the development of the cause and industry of the elderly. On the other hand, as the population ages, elderly consumers have become the main force in the consumer market. However, the empirical research on domestic citizenship behavior of elderly consumers is relatively lacking. Through research, we can further enrich the research on consumer psychology and consumption behavior of elderly consumers, and provide some reference for later research. At the same time, this paper studies customer citizenship behavior from the perspective of value co-creation theory, which can make up for the gap in the research of customer citizenship theory and further expand relevant theoretical research. In addition, the conclusions of this study can provide some opinions for serviceoriented enterprises to promote customer citizenship behavior, stimulate elderly customers purchase intention, improve economic efficiency and further open the market for elderly consumers. Therefore, based on the value creation theory, this paper verifies the influence of customer citizenship behavior on elderly customers purchase intention, and discusses whether aging attitude has a moderating effect on this relationship. This study is divided into six chapters, including introduction, literature review, research hypotheses, research methods, conclusion and management implications as well as limitations and prospects.

\section{Literature Review}

\subsection{Customer Citizenship Behavior Based on Value Co-Creation Theory}

The concept of customer citizenship behavior comes from organizational citizenship behavior, and the research object extends from enterprise employees to corporate customers. Groth (2005) officially proposed the definition of "customer citizenship behavior" for the first time. He believes that customer citizen- 
ship behavior is not necessary in the process of service production or delivery, but the customer voluntarily performs the behavior that is generally beneficial to the organization function and organizational efficiency [4]. On the basis of previous studies, Chen Xinkang (2013) et al. refined the customer citizenship behavior. He proposed the customer citizenship behavior based on the relationship marketing perspective: The non-purchasing or non-consumer pro-business behavior of the customer who is voluntarily implemented based on the emotional and relationship contract in the development process of the enterprise dynamic relationship and which has positively promoted the enterprise value creation, value transfer ability and business performance [5]. Combining the ideas of Prahalad and Ramaswamy (2004) in value co-creation theory, the interaction between members of value network is the basic realization of value co-creation [3]. As equal value subjects, consumers and enterprises create value for themselves and each other through continuous interaction, build a personalized and specialized service experience, and value co-creation through the entire process of consumer and enterprise interaction and the entire formation of consumer experience. Therefore, the connotation of customer citizenship behavior based on value co-creation theory is: in the process of continuous interaction with the company and other customers, the customer helps the company improve their ability of value creation and value transfer, and then promote the overall development of the company by voluntarily implementing a series activities that are not necessary in the process of service production or delivery such as recommendation behavior, help behavior and feedback behavior. At the same time, customers continue to create common values in the continuous interaction with the company, helping companies to continuously update products, optimize service processes, and achieve accurate customer relationship management.

\subsection{Consumer Behavior of Elderly Consumers}

Dekker (1986) called the elderly "time immigrants" [6], meaning that the elderly have spent most of their lives, tasting the ups and downs of the life timeline; their experience will largely affect their consumption behavior. The article sets the age of the elderly to be over 50 years old. At this age, the elderly have just retired or are about to retire. They start to have a lot of free time to do things they are interested in, and consumption has become an indispensable part of their daily lives. However, due to the decline of their own functions, elder consumers' consumption behavior is very different from young consumers, as shown in: 1) consumption information: because the elderly are limited by their own factors, such as the decline of vision and hearing, and the slow learning ability, they can't skillfully use electronic devices such as mobile phones to obtain consumer information in time. According to CNNIC's $42^{\text {nd }}$ China Internet Report, netizens over the age of 50 accounted for a total of $10.5 \%$, accounting for about $30 \%$ of the elderly over the age of 50 . It can be seen that although a small number of elderly people can obtain consumer information through the Internet, most elder- 
ly people do not use the Internet. 2) Consumption pattern: the consumption patterns of the elderly are mainly limited to offline. On the one hand, because the elderly have a lot of free time, they can choose their favorite products or services through offline shopping, and at the same time that can increase their chances of interpersonal interaction. On the other hand, because the elderly are less able to accept new things, online consumption is a new way of consumption for them. The elderly have a resistance to change. Once the familiar lifestyle changes, it will make them feel insecure. 3) Shopping behavior: the elderly have a habitual consumer psychology. Most of the elderly have experienced a hard life when they are young, leading them to maintain a diligent and economical consumption habit. They are much targeted when shopping, choosing among the products they need, and don't blindly consume. 4) Psychological expectation: due to the decline of life ability and psychological deficiency, the elderly hope to obtain psychological compensation for services through consumption. They are eager to receive respect and equal treatment from others, such as the courtesy and help of the service staff, the help of other customers, and the rest of the elderly.

\subsection{Aging Attitude}

Aging is a natural law and a process that everyone has to experience. Kotter-Griihn et al. (2009) defined aging as a process of individual acceptance and adaptation to changes in physiology levels and changes in social status from a psychological perspective. It is a gradual adaptive behavioral approach [7]. The aging attitude is an important psychological variable to measure the physiology, psychology and behavior of the elderly. Laidlaw et al. (2007) argue that aging attitude refers to the individual's feelings and evaluations about their aging. From the nature of content, the aging attitude can be divided into two dimensions: positive and negative. The positive aspect is psychological acquisition. It refers to the positive aging experience of the elderly, such as good physical condition, age-given experience and wisdom, etc. The negative aspect is psychological loss. It refers to the negative aging experience of the elderly, such as the lack of all aspects of the old age and negative experience [8]. Based on the previous studies, this paper defines the aging attitude as a subjective assessment of the individual's aging, which has a certain impact on his physiology, psychology and behavior.

\subsection{Purchase Intention}

Purchase Intention is used to measure the customer's intention to purchase a particular type of product. Dodds (1991) believes that the purchase intention refers to the customer's propensity to purchase a product or service in a specific situation [9]. Through research, Feng Jianying (2006) found that consumers have actually valued products or services before they make purchasing decisions, which means that they must have the intention of trading at the beginning of trading activities. This is called customer purchase intention [10]. At present, 
there are many researches on the antecedent variables of purchasing intention, but there are relatively few studies on customer citizenship behavior as antecedent variables. Therefore, this paper focuses on the impact of customer citizenship behavior on purchase intention.

\section{Research Hypotheses}

\subsection{Customer Citizenship Behavior and Elderly Customer Purchase Intention}

Social exchange theory believes that the essence of the relationship between people is a social exchange relationship, emphasizing the norms and principles of reciprocity, that is, when people are treated positively and politely by others, they will also take appropriate measures to treat others positively and politely. Blau (1964) believes that social exchange refers to the individual's behavior in favor of others, and also hopes to get the return of others, and he points out that the reason why individuals establish relationships with others is to maximize their own interests [11]. The essence of social exchange theory is reciprocity, that is, people must treat each other positively, so that individuals will actively return help from others, and as the reciprocal behavior increases, the social exchange relationship will continue to be strengthened. Therefore, based on the social exchange theory, when the customer makes behaviors that are beneficial to other customers, such as recommendation behaviors and help behaviors, thereby facilitating the consumption process of other customers, in the end, it will also increase the purchasing intention of other customers to a certain extent. When the customer makes behaviors that are beneficial to the company, such as feedback behaviors, recommendation behaviors, and help behaviors, according to the principle of reciprocity of social exchange, the company will actively adopt the customer's suggestion, formulate and implement improvement measures that are beneficial to the customer, and ultimately increase their purchase intention. Based on this, the following hypotheses will be examined:

H1: Customer citizenship behavior has a significant positive impact on the purchasing intention of elderly customers.

H1a: Customer recommendation behavior has a significant positive impact on the purchasing intention of elderly customers.

H1b: Customer help behavior has a significant positive impact on the purchasing intention of elderly customers.

H1c: Customer feedback behavior has a significant positive impact on the purchasing intention of elderly customers.

\subsection{Moderating Effect of Aging Attitude}

According to domestic and international research, aging attitude is an important psychological variable to measure the physical and mental health of the elderly. Positive aging attitude will have a positive impact on the physiology, psychology and behavior of the elderly. Lineweaver et al. (2009) found that memory cogni- 
tive ability changes with age, on the one hand due to neurophysiological function, and to a greater extent due to aging attitude [12]. Domestic scholars Li Chuanyun and Wu Zhenyun (2001) used the direct thinking method to change the aging attitude of the subjects, and used the associative memory and graphic memory to measure the memory scores of the subjects. The final study found that aging attitudes have an impact on the cognitive function of the elderly [13]. Cognitive behavior theory holds that cognition plays an intermediary and coordination role in cognition, emotion and behavior. Cognition interprets individual behavior, which directly affects whether the individual ultimately takes action. In the service situation, the aging attitude has an impact on the cognition of the elderly, and then cognition will affect the interpretation of the customer's citizenship behavior, and ultimately affect the purchasing intention of the elderly to a certain extent. For older people with more psychological acquisitions, they may show more positive cognition. They are more willing to trust others, and they are more accepting of help and recommendation from others. At the same time, they are also more willing to provide practical advice to enterprises. However, for older people with more psychological losses, they may show more negative cognition. They don't trust others easily, and they are less acceptable to other customers' help and recommendation. At the same time, they refuse to communicate with the company, and are reluctant to give feedback to the company. Based on this, the following hypotheses will be examined:

H2: Aging attitude has a moderating effect between customer citizenship behavior and elderly customers purchase intention.

H2a: Aging attitude has a moderating effect between customer recommendation behavior and elderly customers purchase intention.

H2b: Aging attitude has a moderating effect between customer help behavior and elderly customers purchase intention.

H2c: Aging attitude has a moderating effect between customer feedback behavior and elderly customers purchase intention.

In short, this paper constructs an empirical model of three dimensions of customer citizenship behavior to elderly customer purchase intention, and the moderation of age attitude, and uses two statistical software SPSS25 and AMOS23 to verify this model in the following, as shown in Figure 1.

\section{Research Method}

\subsection{Questionnaire Design and Data Collection}

This paper is aimed at people over the age of 50. It measures the impact of customer citizenship behavior on purchase intention in the service context and explores the impact of aging attitude on the relationship between the two. The selection of people over the age of 50 is based on the following considerations: first, under the current policy, the statutory retirement age of employees in China is 60 years old for males, 50 years old for female workers, and 55 years old for female cadres. Therefore, in this paper, in order to make the research more 


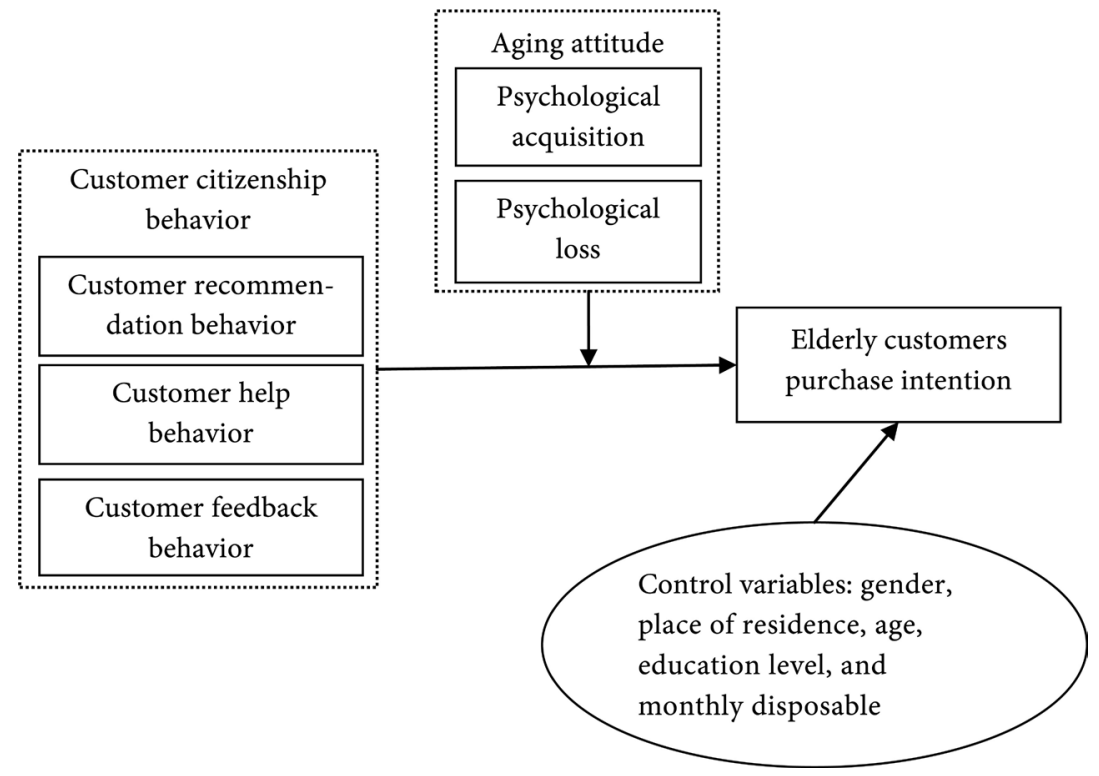

Figure 1. Theoretical framework.

universal, people over 50 years old are selected as research objects. The second is to cover as many people as possible. Although the age of the elderly is above 60 years old, it is considered that the elderly have mastered the electronic media such as WeChat and their own knowledge level, and combined with the actual situation and research significance. Finally, the age of the study subjects is set above 50 years old.

The questionnaire design consists of four parts: demographic variables, customer citizenship behavior, aging attitude and purchase intention. In order to ensure the validity and reliability of the questionnaire, the measurement of variables in this paper draws on the maturity scale of scholars at home and abroad. Control variables are mainly related to: gender, place of residence, age, education level, and monthly disposable amount. The measurement of independent customer citizenship behavior mainly draws on the scale of Groth (2005) [4], Gong and Yi (2008) [14], which is divided into three dimensions: recommendation behavior, help behavior, feedback behavior, and a total of 9 items. The moderator of aging attitude mainly draws on the Aging Attitude Scale (AQA) developed by Laidlaw et al. (2007) [8], and selects two dimensions: psychological loss and psychological acquisition, for a total of 16 items. The purchase intention is mainly based on the scale of Dodda et al. (1991) [9], a total of 3 items. All items in this paper are measured using the Likert 5-point scale, where 1 means full disagreement, 2 means disagreement, 3 means uncertainty, 4 means agreement, and 5 means full agreement.

For the recycling of questionnaires, this paper adopts a combination of online and offline. The online use of WeChat platform is mainly used for distribution. The offline is mainly to issue questionnaires to qualified faculty members and elderly communities on campus. After half a month, a total of 400 questionnaires were collected, of which 144 electronic questionnaires were collected from 
online surveys, and 212 paper questionnaires were collected from offline surveys. 44 copies of the questionnaires that were not carefully completed or incomplete were deleted, and a total of 356 questionnaires were finally available for research, and the effective recovery rate was $89 \%$. Among the effective samples, women accounted for $52 \%, 65.4 \%$ of them lived in cities, $85.6 \%$ of them were in $50-69$ years old, and $71.9 \%$ of them were in high school and below. And $77.2 \%$ of them have 1000 - 3000 yuan every month.

\subsection{Scale Reliability and Validity Analysis}

In this paper, SPSS25 and AMOS23 statistical software are used to analyze the reliability and validity of the sample data. Internal consistency indicators can be used for the test of the reliability of the scale. There are many methods for estimating the internal consistency. The most common one is to estimate with the Cronbach coefficient. The Cronbach coefficient of each scale in this study is greater than 0.7 , indicating that the design of each measurement item is better, the measurement consistency is higher and the internal structure is good, so the questionnaire has good reliability. In terms of verification validity, factor analysis is used. Using AMOS23 software to perform confirmatory factor analysis on each index, $\mathrm{x}^{2} / \mathrm{df}=1.997, \mathrm{CFI}=0.988, \mathrm{GFI}=0.965$, RMSEA $=0.053$, according to the standard given by Bentler (1990) [15], indicating that the measurement model has good discrimination validity. At the same time, the average variance extraction AVE and the combination reliability CR of the customer citizenship behavior scale are 0.548 and 0.783 , respectively. The average variance extraction AVE and the combination reliability CR of the aging attitude scale are 0.612 and 0.825 , respectively. The average variance extraction AVE and combination reliability CR of the purchase intention scale are 0.701 and 0.876 , respectively. The results all meet the standard requirements of more than 0.5 and 0.7 , indicating that the scale used in this paper has good convergence validity.

\subsection{Correlation Analysis}

The mean, standard deviation and correlation coefficient of the study variables are shown in Table 1 .

As can be seen from the above table, customer citizenship behavior is positively correlated with purchase intention $(\beta=0.572, \mathrm{p}<0.01)$. At the same time, the three dimensions of customer citizenship behavior: customer recommendation behavior and purchase intention $(\beta=0.543, \mathrm{p}<0.01)$, customer help behavior and purchase intention $(\beta=0.437, \mathrm{p}<0.01)$, customer feedback behavior and purchase intention $(\beta=0.481, \mathrm{p}<0.01)$ are positively correlated. From this, it is initially determined that customer citizenship behavior and its dimensions are significantly and positively related to the purchase intention.

\subsection{Main Effect Test}

This study used a step-by-step screening strategy to analyze the relationship be- 
tween customer citizenship behavior and the elderly customers purchase intention. The specific results are shown in Table 2 . As can be seen from Table 2, the first to enter the regression model is the customer recommendation behavior, followed by the customer help behavior, and finally the customer feedback behavior. In the final model 3, the correlation coefficient between customer recommendation behavior, customer help behavior, customer feedback behavior and the purchase intention of the elderly is 0.579 , the adjustment coefficient is 0.329 . Thus, the explained variables can be explained by the model more, and the $\mathrm{R}$-squared is higher. The specific results of the stepwise regression are shown in Table 3.

As can be seen from Table 3, when the significance level $\alpha$ is 0.05 , the relationship between the customer recommendation behavior, the customer help behavior, the customer feedback behavior, and the purchase intention of the elderly is significant. In addition, the tolerance is close to 1 , and the variance inflation factor VIF is also close to 1 . It can be seen that the collinearity between the explanatory variables is weak. The standard regression equation is: elderly consumers purchase intention $=0.357$ customer recommendation behavior +0.152 customer help behavior +0.192 customer feedback behavior.

The correlation and regression between the elderly consumers purchase intention and the influencing factors indicate that the customer citizenship behavior

Table 1. Correlation between variables.

\begin{tabular}{ccccccc}
\hline Variables & CCB & CRB & CHB & CFB & AA & PI \\
\hline CCB & 1 & & & & & \\
CRB & $0.880^{* *}$ & 1 & & & & \\
CHB & $0.819^{* *}$ & $0.595^{* *}$ & 1 & & & \\
CFB & $0.858^{* *}$ & $0.650^{* *}$ & $0.524^{* *}$ & 1 & & \\
AA & $0.483^{* *}$ & $0.481^{* *}$ & $0.288^{* *}$ & $0.258^{* *}$ & 1 & \\
PI & $0.572^{* *}$ & $0.543^{* *}$ & $0.437^{* *}$ & $0.481^{* *}$ & $0.597^{* *}$ & 1 \\
Mean & 10.93 & 3.60 & 3.78 & 3.55 & 12.6 & 3.66 \\
S.D. & 2.123 & 0.835 & 0.787 & 0.867 & 9.792 & 0.879 \\
\hline
\end{tabular}

Note: $\mathrm{N}=356,{ }^{*}$ means $\mathrm{p}<0.01,{ }^{\star}$ means $\mathrm{p}<0.05$, the same. CCB Customer Citizenship Behavior, CRB Customer Recommendation Behavior, CHB Customer Help Behavior, CFB Customer Feedback Behavior, AA Aging Attitude, PI Purchase Intention.

Table 2. Summary of the regression model of elderly customers purchase intention.

\begin{tabular}{cccccc}
\hline Models & $\mathrm{R}$ & $\mathrm{R}^{2}$ & Adjust $\mathrm{R}^{2}$ & Estimated Standard Error & Durbin-Watson \\
\hline 1 & $0.543^{\mathrm{a}}$ & 0.295 & 0.293 & 0.739 & \\
2 & $0.561^{\mathrm{b}}$ & 0.315 & 0.311 & 0.730 & \\
3 & $0.579^{\mathrm{c}}$ & 0.335 & 0.329 & 0.720 & 1.575 \\
\hline
\end{tabular}

Note: a. Predictor: (constant), customer recommended behavior; b. predictor: (constant), customer recommended behavior, customer help behavior; c. predictor: (constant), customer recommended behavior, customer help behavior, customer feedback behavior. 
Table 3. Regression coefficient and significance test.

\begin{tabular}{|c|c|c|c|c|c|}
\hline & \multirow{2}{*}{ Models } & \multicolumn{2}{|c|}{ Unstandardized Coefficient } & \multirow{2}{*}{$\begin{array}{c}\text { Standardized Coefficient } \\
\text { Beta }\end{array}$} & \multirow{2}{*}{$\mathrm{t}$} \\
\hline & & B & Standard Error & & \\
\hline \multirow{2}{*}{1} & (constant) & 1.602 & 0.174 & & $9.227^{\star \star}$ \\
\hline & CRB & 0.572 & 0.047 & 0.543 & $12.173^{\star *}$ \\
\hline \multirow{3}{*}{2} & (constant) & 1.256 & 0.202 & & $6.206^{* *}$ \\
\hline & CRB & 0.462 & 0.058 & 0.438 & $7.997^{\star \star}$ \\
\hline & $\mathrm{CHB}$ & 0.197 & 0.061 & 0.176 & $3.209^{* *}$ \\
\hline \multirow{4}{*}{3} & (constant) & 1.119 & 0.204 & & $5.479^{* *}$ \\
\hline & $\mathrm{CRB}$ & 0.357 & 0.066 & 0.339 & $5.448^{* *}$ \\
\hline & $\mathrm{CHB}$ & 0.152 & 0.062 & 0.136 & $2.448^{*}$ \\
\hline & CFB & 0.192 & 0.060 & 0.189 & $3.224^{* *}$ \\
\hline
\end{tabular}

positively affects the elderly consumers purchase intention; the customer recommendation behavior positively affects the elderly consumers purchase intention; the customer help behavior positively affects the elderly consumers purchase intention; customer feedback behavior is positively affecting the elderly consumers purchase intention. The analysis verified the hypotheses H1, H1a, $\mathrm{H} 1 \mathrm{~b}$, and H1c.

\subsection{Moderation Test}

In this paper, we use the model used by Baron and Kenny to examine the statistical test of the aging attitude [16]. If the interaction term of the moderator and the explanatory variable has significant influence on the explanatory variable, it indicates that there is a moderating effect.

The data in Table 4 shows that the impact of customer citizenship behavior on purchase intention is significant. The standardized regression coefficient of the product of customer citizenship behavior and aging attitude to purchase intention is $-1.845(\mathrm{t}=-8.611, \mathrm{p}<0.01)$. This shows that the aging attitude has a moderating effect between customer citizenship behavior and purchase intention. So hypothesis $\mathrm{H} 2$ is supported.

The data in Table 5 shows that the influence of customer recommendation behavior on purchase intention is significant. The standardized regression coefficient of the product of customer recommendation behavior and aging attitude to purchase intention is $-1.715(t=-9.267, \mathrm{p}<0.01)$. This shows that the aging attitude has a moderating effect between customer recommendation behavior and purchase intention. So hypothesis H2a is supported.

The data in Table 6 shows that the influence of customer help behavior on purchase intention is significant, and the standardized regression coefficient of the product of customer help behavior and aging attitude to purchase intention is $-1.177(\mathrm{t}=-5.289, \mathrm{p}<0.01)$. This shows that the aging attitude has a moderating effect between customer help behavior and purchase intention. So hypothesis 
Table 4. Moderating effect of AA between CCB and PI.

\begin{tabular}{|c|c|c|c|c|c|c|c|c|c|}
\hline \multirow{2}{*}{ Models } & \multirow{2}{*}{ Variables } & \multicolumn{4}{|c|}{$\begin{array}{l}\text { Hierarchical Regression } \\
\text { Description Statistics }\end{array}$} & \multicolumn{4}{|c|}{$\begin{array}{c}\text { Description and Statistics } \\
\text { of Variables }\end{array}$} \\
\hline & & $\mathrm{R}$ & $\mathrm{R}^{2}$ & df & $\mathrm{F}$ & B & Standard Error & Beta & $\mathrm{t}$ \\
\hline \multirow[t]{3}{*}{1} & & 0.572 & 0.327 & 1 & $172.258^{\star *}$ & & & & \\
\hline & (constant) & & & & & 1.070 & 0.201 & & $5.324^{\star *}$ \\
\hline & CCB & & & & & 0.237 & 0.018 & 0.572 & $13.125^{* *}$ \\
\hline \multirow[t]{4}{*}{2} & & 0.679 & 0.461 & 2 & $151.182^{\star *}$ & & & & \\
\hline & (constant) & & & & & 1.512 & 0.186 & & $8.121^{\star *}$ \\
\hline & $\mathrm{CCB}$ & & & & & 0.153 & 0.018 & 0.370 & $8.292^{\star \star}$ \\
\hline & $\mathrm{AA}$ & & & & & 0.038 & 0.004 & 0.418 & $9.373^{* *}$ \\
\hline \multirow[t]{5}{*}{3} & & 0.745 & 0.555 & 3 & $146.387^{\star *}$ & & & & \\
\hline & (constant) & & & & & 0.376 & 0.215 & & 1.752 \\
\hline & $\mathrm{CCB}$ & & & & & 0.265 & 0.021 & 0.640 & $12.474^{\star \star}$ \\
\hline & $\mathrm{AA}$ & & & & & 0.188 & 0.018 & 2.091 & $10.536^{\star *}$ \\
\hline & $\mathrm{CCB} \times \mathrm{AA}$ & & & & & -0.013 & 0.002 & -1.845 & $-8.611^{* *}$ \\
\hline
\end{tabular}

Table 5. Moderating effect of AA between CRB and PI.

\begin{tabular}{|c|c|c|c|c|c|c|c|c|c|}
\hline \multirow[t]{2}{*}{ Models } & \multirow[t]{2}{*}{ Variables } & \multicolumn{4}{|c|}{$\begin{array}{l}\text { Hierarchical Regression } \\
\text { Description Statistics }\end{array}$} & \multicolumn{4}{|c|}{$\begin{array}{l}\text { Description and Statistics } \\
\text { of Variables }\end{array}$} \\
\hline & & $\mathrm{R}$ & $\mathrm{R}^{2}$ & $\mathrm{df}$ & $\mathrm{F}$ & B & Standard Error & Beta & $\mathrm{t}$ \\
\hline \multirow[t]{3}{*}{1} & & 0.543 & 0.295 & 1 & $148.192^{* *}$ & & & & \\
\hline & (constant) & & & & & 1.602 & 0.174 & & $9.227^{* *}$ \\
\hline & CRB & & & & & 0.572 & 0.047 & 0.543 & $12.173^{\star *}$ \\
\hline \multirow[t]{4}{*}{2} & & 0.665 & 0.442 & 2 & $139.633^{* *}$ & & & & \\
\hline & (constant) & & & & & 1.904 & 0.158 & & $12.062^{\star *}$ \\
\hline & CRB & & & & & 0.351 & 0.048 & 0.333 & $7.341^{* *}$ \\
\hline & AA & & & & & 0.039 & 0.004 & 0.437 & $9.628^{* *}$ \\
\hline \multirow[t]{5}{*}{3} & & 0.742 & 0.551 & 3 & $144.101^{* *}$ & & & & \\
\hline & (constant) & & & & & 0.712 & 0.191 & & $3.718^{\star *}$ \\
\hline & CRB & & & & & 0.722 & 0.059 & 0.686 & $12.301^{\star *}$ \\
\hline & $\mathrm{AA}$ & & & & & 0.173 & 0.015 & 1.921 & $11.624^{\star *}$ \\
\hline & $\mathrm{CRB} \times \mathrm{AA}$ & & & & & -0.037 & 0.004 & -1.715 & $-9.267^{\star *}$ \\
\hline
\end{tabular}

$\mathrm{H} 2 \mathrm{~b}$ is supported.

The data in Table 7 shows that the impact of customer feedback behavior on purchase intention is significant. The standardized regression coefficient of the product of customer feedback behavior and aging attitude to purchase intention is $-1.466(\mathrm{t}=-8.193, \mathrm{p}<0.01)$. This shows that the aging attitude has a moderating effect between customer feedback behavior and purchase intention. So 
Table 6. Moderating effect of AA between CHB and PI.

\begin{tabular}{|c|c|c|c|c|c|c|c|c|c|}
\hline \multirow[t]{2}{*}{ Models } & \multirow[t]{2}{*}{ Variables } & \multicolumn{4}{|c|}{$\begin{array}{l}\text { Hierarchical Regression } \\
\text { Description Statistics }\end{array}$} & \multicolumn{4}{|c|}{$\begin{array}{c}\text { Description and Statistics } \\
\text { of Variables }\end{array}$} \\
\hline & & $\mathrm{R}$ & $\mathrm{R}^{2}$ & $\mathrm{df}$ & $\mathrm{F}$ & B & Standard Error & Beta & $\mathrm{t}$ \\
\hline \multirow[t]{3}{*}{1} & & 0.437 & 0.191 & 1 & $83.563^{* *}$ & & & & \\
\hline & (constant) & & & & & 1.816 & 0.206 & & $8.810^{* *}$ \\
\hline & $\mathrm{CHB}$ & & & & & 0.488 & 0.053 & 0.437 & $9.141^{\star *}$ \\
\hline \multirow[t]{4}{*}{2} & & 0.658 & 0.433 & 2 & $134.763^{\star \star}$ & & & & \\
\hline & (constant) & & & & & 1.860 & 0.173 & & $10.762^{\star *}$ \\
\hline & $\mathrm{CHB}$ & & & & & 0.323 & 0.047 & 0.289 & $6.901^{* *}$ \\
\hline & AA & & & & & 0.046 & 0.004 & 0.514 & $12.274^{\star *}$ \\
\hline \multirow[t]{5}{*}{3} & & 0.689 & 0.475 & 3 & $106.033^{* *}$ & & & & \\
\hline & (constant) & & & & & 1.032 & 0.229 & & $4.515^{\star *}$ \\
\hline & $\mathrm{CHB}$ & & & & & 0.546 & 0.062 & 0.488 & $8.842^{* *}$ \\
\hline & AA & & & & & 0.144 & 0.019 & 1.599 & $7.646^{* *}$ \\
\hline & $\mathrm{CHB} \times \mathrm{AA}$ & & & & & -0.025 & 0.005 & -1.177 & $-5.289^{\star *}$ \\
\hline
\end{tabular}

Table 7. Moderating effect of AA between CFB and PI.

\begin{tabular}{|c|c|c|c|c|c|c|c|c|c|}
\hline \multirow{2}{*}{ Models } & \multirow{2}{*}{ Variables } & \multicolumn{4}{|c|}{$\begin{array}{l}\text { Hierarchical Regression } \\
\text { Description Statistics }\end{array}$} & \multicolumn{4}{|c|}{$\begin{array}{c}\text { Description and Statistics } \\
\text { of Variables }\end{array}$} \\
\hline & & $\mathrm{R}$ & $\mathrm{R}^{2}$ & df & $\mathrm{F}$ & B & Standard Error & Beta & $\mathrm{t}$ \\
\hline \multirow[t]{3}{*}{1} & & 0.481 & 0.231 & 1 & $106.601^{* *}$ & & & & \\
\hline & (constant) & & & & & 1.926 & 0.173 & & $11.143^{* *}$ \\
\hline & CFB & & & & & 0.488 & 0.047 & 0.481 & $10.325^{\star *}$ \\
\hline \multirow[t]{4}{*}{2} & & 0.641 & 0.411 & 2 & $123.130^{\star *}$ & & & & \\
\hline & (constant) & & & & & 2.174 & 0.153 & & $14.172^{\star *}$ \\
\hline & CFB & & & & & 0.266 & 0.047 & 0.263 & $5.714^{* *}$ \\
\hline & AA & & & & & 0.043 & 0.004 & 0.477 & $10.371^{\star *}$ \\
\hline \multirow[t]{5}{*}{3} & & 0.711 & 0.505 & 3 & $119.834^{* *}$ & & & & \\
\hline & (constant) & & & & & 1.307 & 0.176 & & $7.418^{\star *}$ \\
\hline & CFB & & & & & 0.540 & 0.054 & 0.532 & $9.947^{* *}$ \\
\hline & AA & & & & & 0.159 & 0.015 & 1.766 & $10.839^{* *}$ \\
\hline & $\mathrm{CFB} \times \mathrm{AA}$ & & & & & -0.032 & 0.004 & -1.466 & $-8.193^{\star *}$ \\
\hline
\end{tabular}

hypothesis $\mathrm{H} 2 \mathrm{c}$ is supported.

\section{Conclusions and Management Implications}

\subsection{Conclusions}

1) Customer citizenship behavior positively affects elderly customers purchase intention. 
This research studies the purchasing intention of the elderly consumers from the perspective of customer citizenship behavior, and confirms that the customer citizenship behavior will not only directly affect the purchasing intention of the elderly consumers, but also indirectly affect the purchasing intention of the elderly consumers by affecting the behavior of the enterprise. This reveals the internal mechanism of customer citizenship behavior affecting elderly consumers purchase intention. Elderly consumers create value for the company through customer citizenship behavior. Based on the principle of reciprocity in social exchange theory, the company will also improve the product or service according to elderly customers' needs and feedback, and actively construct personalized and specialized service environment for them. This will help to form positive interactions among elderly consumers, making them willing to act as propagators and defenders of the company, ultimately contributing to their purchase intention.

2) Aging attitude has a moderating effect between customer citizenship behavior and elderly customers purchase intention.

When the elderly consumers get more psychological acquisition, the positive effect of customer citizenship behavior and purchase intention is stronger; when the psychological loss is more, the positive effect of customer citizenship behavior and purchase intention is weakened. The conclusion of this study is consistent with the cognitive behavior theory. For older consumers with more psychological acquisition, they have a positive perception. Thus, they are more willing to show a positive attitude in the consumption process, prefer to have positive interaction with other consumers, and are more willing to actively participate in the value co-creation process of the company. For older consumers with more psychological loss, they have a negative perception when they consume. So they have a negative attitude and are not willing to interact with other customers and company. Therefore, service-oriented enterprises can make up for the psychological loss of the elderly and increase their psychological acquisition through the effective interaction between employees and elderly consumers and provide a comfortable and comfortable consumption environment for the elderly consumers. Then, that can promote the positive effect of customer citizenship behavior on elderly consumers purchase intention.

\subsection{Management Implications}

1) Service-oriented enterprises should promote effective interaction between customers and employees, and between customers and customers.

First, enterprises should incorporate interactive-oriented values into their corporate culture. In operational management, enterprises implement interactive-oriented values at the employee level, encouraging employees to actively interact with elderly consumers and to help them solve problems encountered during consumption. As a result, elderly consumers will increase their loyalty and stickiness to the enterprise and gradually become a fixed consumer of the 
company. Second, enterprises should conduct relevant training for employees who interact with customers. By training interactive skills, companies helps employees understand the consumer psychology of elderly consumers and improve their patience and politeness. Therefore, elderly consumers can feel that they are respected and needed during the interaction process, making up for their sense of loss due to physical aging. Ultimately, enterprises will gain their trust. Third, enterprises can actively guide the interaction between older consumers. Enterprises can set up an elderly consumer association for members and conduct regular exchange meetings. Elderly consumers are free to comment on products and services, or advice on the future of the enterprise. For those feasible suggestions, enterprises can give certain rewards to elderly consumers, such as shopping discounts, monetary rewards, etc. At the same time, enterprises can use existing members to develop more potential consumers and encourage them to recommend and promote their products or services to other consumers around them.

2) Service-oriented enterprises should create a comfortable consumer environment for elderly customers.

First, enterprises should consider the design of the overall layout. The fresh food area should be designed near the entrance to the supermarket, or a clear and simple way to design the sign so that the elderly can quickly find the food area. At the same time, due to the limitations of the physical conditions of the elderly, their physical fitness is weaker than that of young consumers. Therefore, enterprises should provide a special rest area for elderly consumers and arrange some teas, newspapers, and discounted merchandise orders in it. Thus, elderly consumers can communicate in this rest area, which indirectly promotes their purchase intention. Second, enterprises should consider the design of the shopping supplies. Enterprises can add a brake function to supermarket carts. This brake function makes it easy for them to brake effectively when needed, which will avoid some safety issues. In addition, companies can provide reading glasses to elderly consumers. Due to the information fonts on the product are small, reading glasses can help the elderly to read. Third, enterprises should consider the design of the after-sales service. Within the scope of the economy, enterprises can provide after-sales delivery services. Elderly consumers consume a certain amount of energy after shopping. By providing delivery services, enterprises can make elderly consumers feel the intimacy of the enterprise and gradually cultivate their goodwill and trust, which will indirectly increase their willingness to purchase.

\section{Limitations and Prospects}

1) This paper mainly selects the supermarket as a representative of service-oriented enterprises, which has certain limitations. In the future, other service-oriented enterprises, such as hospitals and restaurants, can be explored to investigate whether customer citizenship behavior will also affect elderly cus- 
tomers purchase intention, and whether aging attitude also moderates this relationship.

2) This paper has shown that aging attitude has a moderating effect between customer citizenship behavior and elderly customers purchase intention. In the future, it can be explored whether other variables targeting the elderly also have moderating the relationship between customer citizenship behavior and elderly customers.

3) The research method mainly adopts the questionnaire survey method, and the above conclusion can be further verified by the experimental method in the future.

\section{Conflicts of Interest}

The authors declare no conflicts of interest regarding the publication of this paper.

\section{References}

[1] Di, E., Huang, C.J., Chen, I. and Yu, T. (2010) Organisational Justice and Customer Citizenship Behavior of Retail Industries. Service Industries Journal, 30, 1919-1934. https://doi.org/10.1080/02642060802627533

[2] Prahalad, C.K. and Ramaswamy, V. (2000) Co-Opting Customer Competence. Harvard Business Review, 78, 79-87.

[3] Prahalad, C.K. and Ramaswamy, V. (2004) Co-Creation Experiences: The Next Practice in Value Creation. Journal of Interactive Marketing, 3, 5-14. https://doi.org/10.1002/dir.20015

[4] Groth, M. (2005) Customers as Good Soldiers: Examining Citizenship Behaviors in Internet Service Deliveries. Journal of Management, 31, 7-27. https://doi.org/10.1177/0149206304271375

[5] Chen, X., Shi, W. and Gao, W. (2013) Review and Prospect of Customer Citizenship Behavior Research. Economic Management, 9, 189-199.

[6] Dekker, D.L. (1986) Sociology of the Aged: An Introduction to the Development of the Elderly. Tianjin People's Publishing House, Tianjin.

[7] Kotter-Grühn, D., Kleinspehn-Ammerlahn, A., Gerstorf, D. and Smith, J. (2009) Self-Perceptions of Aging Predict Mortality and Change with Approaching Death: 16-Year Longitudinal Results from the Berlin Aging Study. Psychology \& Aging, 24, 654. https://doi.org/10.1037/a0016510

[8] Laidlaw, K., Power, M.J. and Schmidt, S. (2007) The Attitudes to Ageing Questionnaire (AAQ): Development and Psychometric Properties. International Journal of Geriatric Psychiatry, 22, 367-379. https://doi.org/10.1002/gps.1683

[9] Dodds, W.B., Monroe, K.B. and Grewal, D. (1991) Effects of Price, Brand, and Store Information on Buyers' Product Evaluations. Journal of Marketing Research, 28, 307-319.

[10] Feng, J., Mu, W. and Fu, Z. (2006) A Review of Consumer Purchase Intentions. Modern Management Science, 11, 7-9.

[11] Blau, P.M. (1964) Exchange and Power in Social Life. Wiley, Hoboken.

[12] Lineweaver, T.T., Berger, A.K. and Hertzog, C. (2009) Expectations about Memory Change across the Life Span Are Impacted by Aging Stereotypes. Psychology \& Ag- 
ing, 24, 169. https://doi.org/10.1037/a0013577

[13] Li, C. and Wu, Z. (2001) Study on the Effect of Changing Aging Attitude on Memory Work of the Elderly. Chinese Journal of Gerontology, 21, 3-6.

[14] Yi, Y. and Gong, T. (2008) The Effects of Customer Justice Perception and Affect on Customer Citizenship Behavior and Customer Dysfunctional Behavior. Industrial Marketing Management, 37, 767-783.

https://doi.org/10.1016/j.indmarman.2008.01.005

[15] Chou, C.P. and Bentler, P.M. (1990) Model Modification in Covariance Structure Modeling: A Comparison among Likelihood Ratio, Lagrange Multiplier, and Wald Tests. Multivariate Behavioral Research, 25, 115. https://doi.org/10.1207/s15327906mbr2501_13

[16] Baron, R.M. and Kenny, D.A. (1986) The Moderator-Mediator Variable Distinction in Social Psychological Research: Conceptual, Strategic and Statistical Considerations. Journal of Personality Social Psychology, 51, 1173-1182.

https://doi.org/10.1037/0022-3514.51.6.1173 